\title{
ПОКАЗНИКИ ТРОМБОЦИТОГРАМИ В ПАЦІЕНТІВ У РАННЬОМУ ВІДНОВНОМУ ПЕРІОДІ ІШЕМІЧНОГО ІНСУЛЬТУ
}

\author{
○о. Я. Михалойко ${ }^{1}$, І. В. Жулкевич² \\ ${ }^{1} /$ вано-Франківський національний медичний університет \\ ${ }^{2}$ Тернопільський національний медичний університет імені І. Я. Горбачевського МОз України
}

PЕЗЮМЕ. За результатами тромбоцитограми у пацієнтів, які перенесли ішемічний інсульт, у ранньому відновному періоді відмічаються морфофункціональні зміни тромбоцитів.

Мета - вивчення змін показників тромбоцитограми у пацієнтів із перенесеним ішемічним інсультом у ранньому відновному періоді.

Матеріал і методи. Проведено клініко-лабораторний аналіз 80 хворих, які перенесли гострий некардіоемболічний ішемічний інсульт у ранньому відновному періоді. Серед обстежених було 44 чоловіки та 36 жінок віком $(58,42 \pm 6,9)$ років. Групу контролю склали 30 практично здорових осіб (16 чоловіків та 14 жінок) без тяжкої соматичної патології та порушень мозкового кровообігу в анамнезі віком $(56,7 \pm 4,8)$ років. Тромбоцитограму із визначенням кількості тромбоцитів (PLT), середнього об'єму тромбоцитів (MPV), ширини розподілу тромбоцитів (PDW), кількості великих тромбоцитів (P-LCC) та відсотка великих тромбоцитів (P-LCC) проводили на гематологічному аналізаторі Abacus 30.

Результати. Морфофункціональні показники тромбоцитограми у пацієнтів, які перенесли ішемічний інсульт, характеризуються збільшенням розміру тромбоцитів, тромбокриту, підвищенням кількості та відсотка великих тромбоцитів у порівнянні із групою контролю, що свідчить про вищу функціональну тромбоцитарну активність, тобто підвищену їх агрегаційну здатність.

Висновок. Показники MPV, PCT, P-LCC, P-LCR можуть розглядатися як індикатори тромбоцитарної активності при інсульті у ранньому відновному періоді, що розширює можливості контролю за ефективністю антитромбоцитарної терапії.

КЛЮчОВІ СЛОВА: тромбоцитограма; розмір тромбоцитів; тромбокрит; ранній відновний період ішемічного інсульту.

Вступ. Серцево-судинні захворювання $\epsilon$ однією з основних причин інвалідності та смертності серед населення в усьому світі. Зокрема, щорічно у 16 млн жителів планети розвиваються інсульти, 6 млн з них помирають, переважна більшість потребують сторонньої допомоги і лише 10 \% повертаються до повноцінного життя [1].

Інвалідність унаслідок першого перенесеного інсульту становить 75-80 \%, внаслідок повторного - 95-100 \%. Особливий інтерес становлять випадки повторних порушень мозкового кровообігу, які трапляються у 30 \% хворих впродовж 12 місяців після першого інсульту і у 15 \% протягом перших п'яти років. При цьому доведено, що повторний інсульт має ширший спектр неврологічних, когнітивних і психоемоційних порушень, які обумовлені не тільки повторним вогнищем церебральної ішемії, а й стійкими залишковими явищами після першого інсульту [2].

У зв' язку із цим проблема інсульту набула не тільки медичної, а й соціально-економічної значущості, що потребує невідкладних дій щодо імплементації заходів запобігання розвитку інсульту на популяційному рівні.

У патогенезі розвитку як первинного, так і повторного некардіоемболічного ішемічного інсульту істотну роль відіграє активація тромбоцитарної і плазмової ланки гемостазу. На ґрунті ураженого судинного ендотелію під впливом атерогенних факторів, артеріальної гіпертензії та цукрового діабету при ішемічному інсульті відбувається посилення елімінації тромбоцитів, скорочення часу їх життя та компенсаторна активація тромбоцитопоезу з виділенням у кровотік юних тромбоцитів, що відрізняються більшим розміром та високою реактивністю [1, 3-5].

3 огляду на вищенаведене можна стверджувати, що визначення змін морфологічних форм циркулюючих тромбоцитів може мати клініко-діагностичне значення в констатації тромбоцитарної гіперактивності $[4,6,7]$.

Інформацію про стан тромбоцитарного гемостазу та морфофункціональні особливості кров' яних пластинок можна отримати за результатами оптичної агрегатометрії, а також при дослідженні крові на гематологічному аналізаторі.

Єдиної думки щодо інтерпретації тромбоцитарних показників гемограми на даний момент не існує, частіше трапляються і зовсім суперечливі висловлювання з даного приводу [6, 7, 9-13].

Згідно з даними Bath P. et al., 2004; MaydaDomac F. et al., 2010, збільшення показника MPV відмічається в гострому і ранньому відновному періодах ішемічного інсульту та розглядається як незалежний предиктор розвитку та індикатор тяжкості перебігу інсульту, однак результати до- 
Огляди літератури, оригінальні дослідження, погляд на проблему, випадок з практики, короткі повідомлення слідження інших авторів спростовують цей факт (Muscari A. et al., 2009) [4, 7].

C. Patrono констатовано, що збільшення значення MPV на 1 фл. у пацієнтів, котрі перенесли ішемічний інсульт, супроводжується зростанням на $11 \%$ ризику повторного інсульту впродовж 4 років [6].

Мета-аналіз, проведений у 2010 р. на 3000 осіб, показав, що, незважаючи на прийом подвійної антитромбоцитарної терапії, підвищений MPV був пов' язаний із зростанням смертності після інфаркту міокарда та розвитком рестенозу після коронарної ангіопластики [8]. У іншому дослідженні, проведеному на 600 пацієнтах, було встановлено, що MPV, P-LCR, PDW є незалежними сильними прогностичними факторами серцевої смерті після інфаркту міокарда, що лікувалися черезшкірним коронарним втручанням. При цьому аналіз виживання Каплана - Мейєра фіксував значно вищий 26-місячний рівень смертності у пацієнтів із високим рівнем MPV ( $\geq 11,7$ фл.), ніж у пацієнтів з низьким MPV (<11,7 фл.) (14,6 проти 5,5 \%). Такі ж висновки були встановлені й при підвищених показниках P-LCR ( $\geq 38,1 \%)$, порівняно з низьким P-LCR (<38,1\%) (смертність 13,8 проти 5,8 \%), та зростанням PDW ( $\geq 16$ фл.), що корелювало з вищим рівнем смертності, порівняно з PDW <16 фл. (17,4 проти 6,3\%) [9].

У дослідженнях (Дорн О. Ю., Цикаленко Е. А., 2016; E. Vagdatli et al., 2010 р.) було доведено, що показник тромбоцитограми PLCC при ішемічній хворобі серця також може бути маркером активації тромбоцитарного гемостазу [10].

Існують і кардинально інші, контраверсивні результати досліджень, в яких було показано, що у хворих на цукровий діабет показник MPV не пов'язаний з підвищеною реактивністю тромбоцитів і ризиком виникнення атеротромботичних ускладнень і тому не може розглядатися як фактор ризику серцево-судинних захворювань $[11,12]$.

Наявність різноспрямованих думок та тверджень, відсутність чітких відповідей на запитання щодо ролі морфофункціональних змін тромбоцитів у ранньому відновному періоді ішемічного інсульту зумовила наш інтерес до вказаної тематики дослідження. Крім того, ми вважаємо, що оцінювання змін даних тромбоцитограми має бути комплексним, з урахуванням усіх її показників, а не окремих компонентів, оскільки всі складові взаємопов'язані та є відображенням патологічних процесів, що відбуваються в організмі.

Мета - вивчення змін показників тромбоцитограми у пацієнтів із перенесеним ішемічним інсультом у ранньому відновному періоді.

Матеріал і методи дослідження. Проведено клініко-лабораторний аналіз 80 хворих із пе-

ренесеним гострим некардіоемболічним ішемічним інсультом у ранньому відновному періоді (від 3 до 6 міс. після ГРМК). Серед обстежених було 44 чоловіки та 36 жінок віком $(58,42 \pm 6,9)$ років.

Групу контролю склали 30 практично здорових осіб (16 чоловіків та 14 жінок) без тяжкої соматичної патології та порушень мозкового кровообігу в анамнезі віком $(56,7 \pm 4,8)$ років.

Тромбоцитограму із визначенням кількості тромбоцитів (PLT), середнього об'єму тромбоцитів (MPV), ширини розподілу тромбоцитів (PDW), кількості великих тромбоцитів (P-LCC) та відсотка великих тромбоцитів (P-LCC) проводили на гематологічному аналізаторі Abacus 30. Використовували венозну кров, отриману шляхом пункції серединної ліктьової вени, оскільки при цьому клітини крові зазнають меншого механічного пошкодження, аніж при використанні капілярної крові. Кров поміщали у стандартні вакуумні пробірки з готовим концентратом антикоагулянта ЕДТА. Принцип роботи гематологічного аналізатора автоматизований та заснований на зчитуванні вихідної інформації (ємності електричного опору і світлорозсіювання) в пробі крові.

Для статистичної обробки було використано програмне забезпечення STATISTICA 8 software (StatSoft, Serial STA862D175437Q). Для опрацювання отриманих даних використовували непараметричні методи. Результати наводили у вигляді медіани (Ме) та міжквартильного інтервалу [Q25 \%; Q75 \%]. Кількісні показники з ненормальним розподілом значень у 2 незалежних групах порівнювали методом Mann - Whitney. Статистично достовірною вважали різницю $\mathrm{p}<0,05$ між порівнюваними вибірками.

Результати й обговорення. Достовірної різниці між показниками кількості тромбоцитів (PLT) у пацієнтів досліджуваних груп не було, їх діапазон коливався в межах норми і становив 247-262 тис./мкл. При порівнянні середньої величини тромбоцитів (MPV) було встановлено, що у пацієнтів із перенесеним ішемічним інсультом відмічається достовірне збільшення середньої величини тромбоцитів (MPV), порівняно із пацієнтами контрольної групи. Зіставивши тромбокрит обстежуваних груп ми відмітили його зростання у пацієнтів після перенесеного інсульту. Крім того, фіксували достовірно більшу кількість та відсоток великих тромбоцитів, порівняно з групою контролю.

Незважаючи на той факт, що більшість показників тромбоцитограми у досліджуваній групі достовірно відрізнялися від показників групи контролю, вони балансували в межах референтних значень норми. Проте слід врахувати, що пацієнти, які перенесли інсульт, на момент обстеження 
Огляди літератури, оригінальні дослідження, погляд на проблему, випадок з практики, короткі повідомлення приймали антитромбоцитарну терапію та статини з метою вторинної профілактики інсульту, яка,

впливаючи на судинно-тромбоцитарний гемостаз, сприяє зміні даних показників також (табл. 1).

Таблиця 1. Показники тромбоцитограми пацієнтів у ранньому відновному періоді ішемічного інсульту, Me [Q25 \%; Q75 \%]

\begin{tabular}{|l|c|c|}
\hline \multicolumn{1}{|c|}{ Показники } & $\begin{array}{c}\text { Контрольна група } \\
(\mathrm{n}=30)\end{array}$ & $\begin{array}{c}\text { Хворі PBПII } \\
(\mathrm{n}=80)\end{array}$ \\
\hline Кількість тромбоцитів, (тис./мкл) (PLT) & $262,2[218,8 ; 279,7]$ & $247,3[208,5 ; 292,3]$ \\
\hline Відсоток тромбоцитів, \% (PCT) & $0,23[0,20 ; 0,25]$ & $0,28[0,26 ; 0,32]^{*}$ \\
\hline Середній о6'єм тромбоцитів, фл. (MPV) & $8,1[7,65 ; 8,24]$ & $10,7[9,51 ; 10,19]^{*}$ \\
\hline Ширина розподілу тромбоцитів, \% (PDW) & $12,1[11,5 ; 14,3]$ & $13,07[12,6 ; 15,06]$ \\
\hline Кількість великих тромбоцитів, × 109/л (P-LCC) & $58,1[55,5 ; 62,3]$ & $70,4[68,7 ; 75,5]^{*}$ \\
\hline Відсоток великих тромбоцитів, \% (P-LCR) & $27,7[25,5 ; 34,3]$ & $38,6[36,8 ; 40,7]^{*}$ \\
\hline
\end{tabular}

Примітка. * $\mathrm{p}<0,05$ вірогідність відмінностей показників досліджуваної групи відносно групи контролю.

Отримані дані свідчать про підвищений рівень молодих, незрілих, більших за розміром тромбоцитів у пацієнтів із перенесеним ішемічним інсультом у ранньому відновному періоді, порівняно із даними показниками групи контролю, що підтверджує підвищену агрегаційну здатність тромбоцитів пацієнтів досліджуваної групи. Результати цього дослідження збігаються із даними літератури, де зазначено, що тромбоцити більшого розміру мають підвищену агрегаційну здатність та можуть розглядатися як маркери тромбоцитарної гіперактивності та бути предикторами виникнення серцево-судинних катастроф, оскільки активація та агрегація тромбоцитів відіграють ключову роль як у патогенезі атеросклерозу, так і в розвитку гострих тромботичних подій.

Висновки. Морфофункціональні показники тромбоцитограми у пацієнтів, які перенесли іше- мічний інсульт, характеризуються збільшенням розміру тромбоцитів, тромбокриту, підвищенням кількості та відсотка великих тромбоцитів, порівняно з групою контролю, що свідчить про вищу функціональну тромбоцитарну активність, тобто підвищену їх агрегаційну спроможність. Враховуючи цей факт, показники MPV, PCT, P-LCC, P-LCR можуть розглядатися як індикатори тромбоцитарної активності при інсульті у ранньому відновному періоді, що розширює можливості контролю за ефективністю антитромбоцитарної терапії.

Перспективи подальших досліджень передбачають дообстеження пацієнтів РВПІІ та встановлення відповідності гіперагрегації тромбоцитів згідно з результатами проведення оптичної агрегатометрії.

\section{ЛІТЕРАТУРА}

1. Understanding and improving cardiovascular health: an update on the American Heart Association's concept of cardiovascular health / C. M. Shay, H. S. Gooding, R. Murillo, R. Foraker // Prog. Cardiovasc. Dis. - 2015. Vol. 58 (1). - P. 41-49.

2. 2018 Guidelines for the early management of patients with acute ischemic stroke a guideline for healthcare professionals from the American Heart Association/ American Stroke Association / W. J. Powers, A. A. Rabinstein, T. Ackerson [et al.] // Stroke. - 2018. - Vol. 49 (3). P. 1161-1163.

3. Platelet function tests: a comparative review / R. Paniccia, R. Priora, A. Alessandrello, R. Abbate // Vasc. Health Risk Manag. - 2015. - Vol. 2015 (11). - P. 133-148.

4. Thon J. N. Platelets: production, morphology and ultrastructure / J. N. Thon, J. E. Italiano. // Antiplatelet Agents. Handbook of Experimental Pharmacology / P. Gresele, G. Born, C. Patrono, C. Page Eds.- Berlin: Springer, Heidelberg, 2012. Vol. - 210. Available at: https://doi. org/10.1007/978-3-642-29423-5_1
5. Guidelines for laboratory investigation of heritable disorders of platelet function / P. Harrison, I. Mackie, A. Mumford [et al.] // Br. J. Hematol. - 2014. - Vol. 155 (1). - P. 30-44.

6. Davi G. Platelet activation and atherothrombosis / G. Davi, C. Patrono // N. Engl. J. Med. - 2007. - Vol. 357 (24). - P. 2482-2494.

7. Stroke or coronary artery disease prediction from mean platelet volume in patients with type 2 diabetes mellitus / J. Y. Han, D. H. Choi, S. W. Choi [et al.] // Platelets. 2013. - Vol. 24 (5). - P. 401-406.

8. Mean platelet volume as a predictor of cardiovascular risk: a systematic review and meta-analysis / S. G. Chu, R. C. Becker, P. B. Berger [et al.] // J. Thromb. Haemost. 2010. - Vol. 8 (1). - P. 148-156.

9. Prognostic value of platelet indices after acute myocardial infarction treated with primary percutaneous coronary intervention / T. Rechciński, A. Jasińska, J. Foryś [et al.] // Cardiol. J. - 2013. - Vol. 20 (5). - P. 491-498.

10. Platelet distribution width: a simple, practical and specific marker of activation of coagulation / E. Vagdatli, 
Огляди літератури, оригінальні дослідження, погляд на проблему, випадок з практики, короткі повідомлення E. Gounari, E. Lazaridou [et al.] // Hippokratia. - 2010. Vol. 14 (1). - P. 28-32.

11. Mean platelet volume is not associated with platelet reactivity and the extent of coronary artery disease in diabetic patients / G. De Luca, M. Verdoia, E. Cassetti [et al.] // Blood Coagul. Fibrinolysis. - 2013. Vol. 24 (6). - P. 619-624.

12. Combination between mean platelet volume and platelet distribution with to predict the prevalence and

extent of coronary artery disease: results from a large cohort study / G. De Luca, G. G. Secco, M. Verdoia [et al.] // Blood Coagul. Fibrinolysis. - 2014. - Vol. 25 (1). - P. 86-91.

13. Вивчення впливу віку та індексу коморбідності на ризик тромботичних ускладнень у хворих на рак ендометрія на доопераційному етапі / Б. Д. Кривокульський, І.В.Жулкевич, Д. Б. Кривокульський, Л. В. Шкробот // Вісник наукових досліджень. - 2018. - № 2 (91). C. 151-153.

\section{REFERENCES}

1. Shay, C.M., Gooding, H.S., Murillo, R., \& Foraker, R. (2015). Understanding and improving cardiovascular health: an update on the American Heart Association's concept of cardiovascular health. Prog. Cardiovasc. Dis, 58 (1), 41-49. DOI: $10.1016 /$ j.pcad.2015.05.003

2. (2018). 2018 Guidelines for the early management of patients with acute ischemic stroke a guideline for healthcare professionals from the American Heart Association/American Stroke Association. Stroke, 49(3), 1161-1163. DOI: 10.1161/STR.0000000000000158

3. Paniccia, R., Priora, R., Alessandrello, A., \& Abbate, R. (2015). Platelet function tests: a comparative review. Vasc. Health Risk Manag., 2015 (11), 133-148. DOI: $10.2147 /$ VHRM.S44469

4. Thon, J.N., \& Italiano, J.E. (2012). Platelets: production, morphology and ultrastructure. In: Gresele P., Born G., Patrono C., Page C. Eds. Antiplatelet Agents. Handbook of Experimental Pharmacology. Berlin: Springer, Heidelberg. DOI: 10.1007/978-3-642-29423-5_1

5. Harrison, P., Mackie, I., Mumford, A., Briggs, C., Liesner, R., Winter, M., \& Machin, S. (2014). Guidelines for laboratory investigation of heritable disorders of platelet function. Br. J. Hematol., 155 (1), 30-44. DOI: 10.1111/j.1365-2141.2011.08793.x

6. Davi, G., \& Patrono, C. (2007). Platelet activation and atherothrombosis. N. Engl. J. Med., 357 (24), 2482-2494. DOI: 10.1056/NEJMra071014

7. Han, J.Y., Choi, D.H., Choi, S.W., Kim, B.B., Ki, Y.J., Chung, J.W., \& Hong, S.P. (2013). Stroke or coronary artery disease prediction from mean platelet volume in patients with type 2 diabetes mellitus. Platelets, 24 (5), 401-406. DOI: 10.3109/09537104.2012.710858

8. Chu, S.G., Becker, R.C., Berger, P.B., Bhatt, D.L., Eikelboom, J.W., Konkle, B., \& Berger, J.S. (2010). Mean platelet volume as a predictor of cardiovascular risk: a

systematic review and meta-analysis. J. Thromb. Haemost., 8(1), 148-156. DOI: 10.1111/j.1538-7836.2009.03584.x

9. Rechciński, T., Jasińska, A., Foryś, J., KrzemińskaPakuła, M., Wierzbowska-Drabik, K., Plewka, M., \& Kasprzak, J.D. (2013). Prognostic value of platelet indices after acute myocardial infarction treated with primary percutaneous coronary intervention. Cardiol. J., 20 (5), 491-498. DOI: 10.5603/CJ.2013.0134

10. Vagdatli, E., Gounari, E., Lazaridou, E., Katsibourlia, E., Tsikopoulou, F., Labrianou, I. (2010). Platelet distribution width: a simple, practical and specific marker of activation of coagulation. Hippokratia, 14 (1), 28-32.

11. De Luca, G., Verdoia, M., Cassetti, E., Schaffer, A., Di Giovine, G., Bertoni, A., \& Sinigaglia, F. (2013). Mean platelet volume is not associated with platelet reactivity and the extent of coronary artery disease in diabetic patients. Blood Coagul. Fibrinolysis, 24 (6), 619-624. DOI: 10.1097/MBC.0b013e328360c75a

12. De Luca, G., Secco, G.G., Verdoia, M., Cassetti, E., Schaffer, A., Coppo, L., \& Marino, P. (2014). Combination between mean platelet volume and platelet distribution with to predict the prevalence and extent of coronary artery disease: results from a large cohort study. Blood Coagul. Fibrinolysis, 25 (1), 86-91. DOI: 10.1097/ MBC.0b013e32836577a8

13. Kryvokulsky, B.D., Zhulkevich, I.V., Kryvokulsky, D.B., \& Shkrobot, L.V. (2018). Vyvchennia vplyvu viku ta indeksu komorbidnosti na ryzyk trombotychnykh uskladnen u khvorykh na rak endometriia na dooperatsiinomu etapi [Studying the influence of age and comorbidity index on the thrombotic complications risk in patients with endometrial cancer at preoperative stage]. Visnyk naukovykh doslidzhen - Bulletin of Scientific Research, 2 (91), 151-153. DOI: https://doi.org/10.11603/2415-8798.2018.2.9212 [in Ukrainian]. 
Огляди літератури, оригінальні дослідження, погляд на проблему, випадок з практики, короткі повідомлення ПОКАЗАТЕЛИ ТРОМБОЦИТОГРАММЫ У ПАЦИЕНТОВ В РАННЕМ
ВОССТАНОВИТЕЛЬНОМ ПЕРИОДЕ ИШЕМИЧЕСКОГО ИНСУЛЬТА

๑о. Я. Михалойко1, И. В. Жулкевич²

${ }^{1}$ Ивано-Франковский национальный медицинский университет

${ }^{2}$ Тернопольский национальный медицинский университет имени И. Я. Горбачевского МОз Украины

РЕзюмЕ. По результатам тромбоцитограммы у пациентов, перенесших ишемический инсульт, в раннем восстановительном периоде отмечаются морфофункциональные изменения тромбоцитов.

Цель - изучение изменений показателей тромбоцитограммы у пациентов с перенесенным ишемическим инсультом в раннем восстановительном периоде.

Материал и методы. Проведен клинико-лабораторный анализ 80 больных, перенесших острый некардиоемболический ишемический инсульт в раннем восстановительном периоде. Среди обследованных было 44 мужчины и 36 женщин в возрасте $(58,42 \pm 6,9)$ лет. Группу контроля составили 30 практически здоровых лиц (16 мужчин и 14 женщин) без тяжелой соматической патологии и нарушений мозгового кровообращения в анамнезе, в возрасте $(56,7 \pm 4,8)$ лет. Тромбоцитограмму с определением количества тромбоцитов (PLT), среднего объема тромбоцитов (MPV), ширины распределения тромбоцитов (PDW), количества больших тромбоцитов (P-LCC) и процента крупных тромбоцитов (P-LCC) проводили на гематологическом анализаторе Abacus 30.

Результаты. Морфофункциональные показатели тромбоцитограммы у пациентов, перенесших ишемический инсульт, характеризуются увеличением размера тромбоцитов, тромбокрита, повышением количества и процента крупных тромбоцитов по сравнению с группой контроля, что свидетельствует о высшей функциональной тромбоцитарной активности, то есть об их повышенной агрегационной способности.

Выводы. Показатели MPV, PCT, P-LCC, P-LCR могут рассматриваться как индикаторы тромбоцитарной активности при инсульте в раннем восстановительном периоде, что расширяет возможности контроля за эффективностью антитромбоцитарной терапии.

КЛЮЧЕВЫЕ СЛОВА: тромбоцитограмма; размер тромбоцитов; тромбокрит; ранний восстановительный период ишемического инсульта.

\title{
THROMBOCYTOGRAM PARAMETERS IN PATIENTS OF EARLY RECOVERY PERIOD OF ISCHEMIC STROKE
}

\author{
๑O. Ya. Mykhaloiko', I. V. Zhulkevych² \\ ${ }^{1}$ Ivano-Frankivsk National Medical University \\ ${ }^{2}$ I. Horbachevsky Ternopil National Medical University
}

SUMMARY. According to the results of the thrombocytogram in patients with ischemic stroke in the early recovery period there are morphofunctional changes in platelets.

The aim - changes in thrombocytogram parameters in patients with ischemic stroke in the early recovery period.

Material and Methods. A clinical and laboratory analysis of 80 patients with acute noncardioembolic ischemic stroke in the early recovery period. Among those surveyed were 44 men and 36 women age (58.42 \pm 6.9$)$ years. The control group consisted of 30 healthy individuals (16 men and 14 women) without severe somatic pathology and a history of cerebrovascular disorders, age $(56.7 \pm 4.8)$ years. Platelet count $(P L T)$, mean platelet volume $(M P V)$, platelet distribution width (PDW), large platelet count (P-LCC) and large platelet percentage (P-LCC) were performed on an Abacus 30 hematology analyzer.

Results. Morphofunctional parameters of the platelet in patients with ischemic stroke are characterized by an increase in platelet size, platelet count, increase in the number and percentage of large platelets compared with the control group, indicating higher functional platelet activity, i.e increased aggregation capacity.

Conclusion: Indicators of MPV, PCT, P-LCC, P-LCR, can be considered as indicators of platelet activity in stroke in the early recovery period, which expands the possibilities of monitoring the effectiveness of antiplatelet therapy.

KEY WORDS: thrombocytogram; platelet size; thrombocrit; early recovery period of ischemic stroke.

Отримано 18.03.2021 